\title{
LA MEXICANIDAD DE JUAN RUIZ DE ALARCÓN
}

\author{
POR \\ DAVID H. DARST \\ Florida State University
}

Al enumerar el gran "cuatrillo" dramático español del Siglo de Oro, siempre se incluye con Lope de Vega, Tirso de Molina y Calderón de la Barca al mexicano Juan Ruiz de Alarcón. La inclusión de éste es una anomalía profesional, dado que sus obras no eran tan populares durante su vida, ni después, hasta el siglo veinte. Si fueron conocidas en España o el extranjero antes de 1900, era más bien por inspirar el Menteur de Corneille y la Ecole de maris de Molière. ¿Por qué, entonces, incluir a Ruiz de Alarcón en dicho "cuatrillo" cuando Guillén de Castro, Mira de Amescua, Vélez de Guevara y Pérez de Montalbán (que son sólo unos de cuantos) escribían más comedias y eran más populares que el mexicano, aunque no han logrado ni cerca de la fama de éste hoy en día?

La popularidad actual de Ruiz de Alarcón, según Walter Poesse (125-27) proviene sin duda de su abolengo americano, el cual fue "descubierto" como el factor más influyente en su sensibilidad dramática por José María Vigil, en 1908, y fue propagado como acta de fe en 1914 por Pedro Henríquez Ureña. Nadie dudó de la supuesta "mexicanidad" de Ruiz de Alarcón hasta los años cincuenta, cuando Ermilo Abreu Gómez puso en duda la posibilidad de usar el término "mexicano" en 1600, cuando los españoles allí se consideraban más bien "colonos" (ni siquiera "criollos") trasladados de su verdadera patria (xii-xiii). En 1959, Alva V. Ebersole propuso otra vez una "españolidad" para dicho dramaturgo ( $E l$ ambiente español), y en 1964 Antonio Alatorre taló definitivamente la idea de un alma mexicana para Ruiz de Alarcón. Sin embargo, y a pesar de seguir paso a paso las reglas del Arte nuevo de Lope, revelado en la conformidad de sus obras a un análisis críticoliterario tradicional de la comedia (Delgado, Foley “The Structure ...," Rodríguez Cepeda), hay mucho en los dramas de Juan Ruiz de Alarcón que los hacen lo que Alison Weber ha llamado "agenéricos" y que los distinguen de la típica comedia lopesca.

Curiosamente, se sabe más del aspecto físico de Ruiz de Alarcón que de su vida, porque, según los comentarios de la época, era sumamente feo: un pelirrojo jorobado que recibió maliciosos ataques escritos y verbales de todos los escritores contemporáneos (Fernández-Guerra, Jiménez Rueda). Muchos han opinado que estos aspectos físicos, combinados con el hecho que Ruiz de Alarcón era un forastero, un intruso, son los factores que hay que tomar en cuenta al estudiar las anomalías estílisticas y estructurales de su producción dramática. Jaime Concha, en particular, ha alegado que el origen y la naturaleza de la dramática alarconiana se basan en la deformidad individual del escritor, su carácter 
de segundón, su pertenencia al grupo de los letrados, su posición inestable en la nobleza media de su época (era un noble emprobrecido pero con familia y mecenas poderosos) y, por último, en su condición de indiano. Pero, como se demostrará en este ensayo, lo más importante de Alarcón es la paradoja cultural notada por Ermilo Abreu Gómez: "Si ayer le llamaron el intruso, nosotros debemos llamarle hoy nuestro verdadero hijo pródigo. $\mathrm{Y}$ repitamos esta especie de paradoja: fue mexicano en la medida en que le fue imposible ser español" (xiv).

¿Cuáles son, entonces, las anomalías y rarezas que expresa Ruiz de Alarcón exclusivamente "en la medida en que le fue imposible ser español"? Primero, a pesar de seguir el mismo patrón dramático hispano de los demás barrocos españoles (Partida 33), hay varios puntos técnicos en su repertorio que le distancian de Lope, Tirso y Calderón. Uno es su uso de la tramoya. Mientras sus colegas usaron máquinas teatrales exclusivamente en comedias de santos y comedias mitológicas, y en ningún otro género (Darst, "El matrimonio"), Ruiz de Alarcón emplea la tramoya al azar a través de todos los géneros con fines puramente teatrales, sin relación aparente con el argumento de la obra. Se destacan en especial sus comedias de magia (un género exclusivamente suyo) La cueva de Salamanca, La manganilla de Melilla, La prueba de las promesas y la atribuida Quien mal anda en mal acaba (Foley, Occult Arts).

Otro punto es la mezcla total de temas y argumentos que otros dramaturgos normalmente no combinaron, en particular la mezcla de asuntos históricos serios con los omnipresentes enredos amorosos que llevan a un emparejamiento final de los galanes con sus damas. Mientras Tirso, por ejemplo, casi nunca termina sus dramas históricos con matrimonios (Darst, "El matrimonio"), nuestro americano no ve ningún inconveniente en cerrar sus comedias históricas con finales más bien destinados para las comedias de enredo, rellenando obras bien serias como Los pechos privilegiados y La crueldad por el honor con estructuras cómicas: intrigas amorosas, triángulos, identificaciones erróneas, conclusiones equivocadas, multiples enredos y muchísimas bodas. $Y$ todo esto en dos dramas que Ruiz de Alarcón jura ser "verdadera historia" en sus últimas líneas, con fuentes específicas citadas allí. En efecto, Alarcón declaró al final de ocho de sus comedias que eran "verdadera historia". Uno se pregunta por qué toda "historia" no es "verdadera" de antemano, y por qué el mexicano insiste en usar esta frase, cuando nunca usa los términos genéricos "tragedia," "tragicomedia," etc., y cuando es usada para describir obras tan diversas como son La prueba de las promesas, basada en un cuento de El Conde Lucanor, y La manganilla de Melilla, de una base histórica de poco mérito.

Otro aspecto técnico predominante en Alarcón es la violencia, la cual es sumamente exagerada, especialmente en El anticristo y El tejedor de Segovia. No se tiene a ningún autor del siglo diecisiete que dramatice momentos tan violentos como los que son tan comunes en las obras del mexicano.

Por último, hay una verdadera falta de espíritu contrarreformista en las comedias de Ruiz de Alarcón, como, por ejemplo, en el uso de la religión; porque donde la haya, el dramaturgo pasa por encima de ella o la presenta mal en sutiles debates o soliloquios pesados o la coloca "beneath the plot's surface" (Hegyl 261). Relacionada con esto es su actitud sobre la magia, en la cual cree y cuya existencia nunca niega, aunque siempre termina sus dramas con la condena de su práctica por ser diabólica (Foley, Occult Arts). 
Si Ruiz de Alarcón estuviera escribiendo en los años ochenta y noventa del "cinquecento", antes de que Lope de Vega renovara la comedia, se podría denominar las susodichas peculiaridades teatrales características del Manierismo, cuyos rasgos más evidentes en España eran el uso de técnicas artísticas para fines no apropiados al medio, la confusión y mezcla de géneros artísticos y la imitación del estilo de otro en vez de la naturaleza (Darst, "Mannerism" 92). Todos éstos describen lo que hace Ruiz de Alarcón con sus comedias, y no tienen nada que ver con las normas genéricas seguidas por Lope y Tirso, por ejemplo.

¿A qué se debe tanta divergencia de las normas dramáticas? Quizá se puede alegar la disculpa de extranjería, ya que Ruiz de Alarcón no estuvo en España para ver nacer y desarrollarse la comedia nueva. Llegó tarde y vio sólo el resultado final; así usó los motivos, temas, técnicas, tramoyas y estructuras genéricas en la manera que más le convenía o le parecía apropiada. En un nivel más intuitivo, se puede afirmar también de él una cierta inocencia e ingenuidad en cuando a personajes y argumentos. El espectador de una comedia de Ruiz de Alarcón no está nunca engañado sobre la verdad de los asuntos, la identidad verdadera de los caracteres, o las suposiciones y conclusiones que expresan algunos personajes sobre la identidad o las intenciones de los demás. Los espectadores siguen así las diferentes maquinaciones del argumento, plenamente conscientes de todo, observadores onmiscientes, como Dios, de las vidas de los personajes, sabiendo lo que ellos no saben pero que efectivamente necesitan saber para evitar las complicaciones a las cuales se someten para alcanzar su meta (la cual es normalmente casarse con el cónyuge apropiado). Son los personajes, en otras palabras, y no los espectadores los que se sienten agobiados por el típico problema barroco de "las apariencias engañan".

El desplazamiento de las confusiones y equivocaciones de la mente de los espectadores a los personajes dramáticos y su interacción mutua crea una relación igualmente cándida y sencillista entre el espectador y su sentido del suspenso dramático. No lo hay, puesto que el espectador siempre sabe quiénes son los "disfrazados" y qué piensan hacer o quieren conseguir, con la excepción de la acción en La crueldad por el honor, donde al autor esconde el verdadero linaje de Sancho hasta el final del drama. Por eso el suspenso tiene que surgir de la acción y no del discurso dramático. Los personajes se presentan ante nosotros, hacen planes y suposiciones sobre sus vidas y sus relaciones con los demás, y luego actúan según esta información. Sus planes normalmente se tuercen, y al final de la comedia descubren que la situación no era ni como quisieron ni como imaginaron; y por eso en los desenlaces unos son premiados, pero nunca todos. A nosotros en el siglo veinte estos finales nos parecen bastante anómalos, si no arbitrarios.

De igual interés es la presentación de la mujer en las obras de Ruiz de Alarcón, o más bien la falta de presentación; porque, como ha observado Walter Poesse,

Alarcón's ladies are generally of three types: the malicious schemer who loses out, the 'good' schemer who triumphs, and a large number of rather colorless, shadowy women. For all of their excellent qualities, Dona Ana of The Walls Have Ears, Lucrecia and Jacinta of The Truth Suspect, and Doña Blanca of The Test of Promises, to mention the ladies of Alarcón's three best plays, never rise to being much more than pawns. Several of his damas give great promise of being spirited and independent, with a mind of their own, but the promise is usually short-lived (111). 
A pesar de recientes defensas vigorosas de la mujer alarconiana por Pasto y Severin, es válido preguntar dónde están los tipos famosos de la comedia lopesca y tirsiana: la mujer varonil, la mujer vestida de hombre, la mujer desesperada, la bandolera, la pastora, la serrana y el sinnúmero de protagonistas que dieron sus nombres o epítetos al título de obras sobre la dama boba, la moza del cántaro, la villana de Getafe o de Vallecas o de la sagra. Sorprende pensar que Jimena en Los pechos privilegiados es lo mejor que Alarcón puede idear en esta área tan decisiva de la comedia del Siglo de Oro, un área tan crítica que Bruce W. Wardropper considera el éxito de la dama en lograr sus deseos, sean personales, matrimoniales o políticos, el ingrediente más importante de la naturaleza de la comedia española del Siglo de Oro:

\begin{abstract}
Normalmente la comedia urbana española nos muestra el triunfo de las mujeres sobre los hombres. Las damiselas burlan a sus guardianes y a sus pretendientes no deseados, manipulando sucesos y personas hasta garantizar que no han de casarse con nadie que no sea el joven del que están enamoradas. En el escenario se conducen de forma contraria a las convenciones - y a la moral, a veces - para lograr sus propósitos. ... Aunque escrita por hombres, la comedia adopta un punto de vista feminino. Es como si el dramaturgo varón, para compensar a las víctimas de la injusta sociedad ideada por los de su sexo, prestase atención por una vez al papel de manipuladores que la sociedad masculina ha obligado a tomar a la mujer (221 y 226).
\end{abstract}

No es por nada que Wardropper no cita ni a Juan Ruiz de Alarcón ni a ninguna obra suya en ninguna parte del libro. El hecho es que no se encuentran protagonistas femeninas en el teatro de Alarcón. Hay solamente damas y damas rivales (normalmente una en cada obra) que compiten pasivamente por una oportunidad de casarse con el hombre que piensan hacer su cónyuge apropiado, y aún así están por la mayor parte equivocadas y terminan casándose con otro inesperado. Este rasgo es seguramente el más obvio que distancia a Ruiz de Alarcón de sus contemporáneos peninsulares, aunque sería difícil alegar una "mexicanidad" en ello.

Queda, por último, lo que se propone como una señal claramente indicadora de que Ruiz de Alarcón no es europeo, ¡y mucho menos "español"! Falta en su teatro una filosofía coherente típica de una mentalidad occidental; o sea, una sustancia intelectual - absorbida por el individuo de la cultura en que nace y se desarrolla - claramente heredada de las tradiciones greco-romano-cristianas del mundo mediterráneo. Se ha dicho, por ejemplo, que Lope es platonista, que Tirso es aristotélico, que Calderón expresa una actitud neoescolástica y que el pensamiento de Quevedo es de un estoicismo puro. Ruiz de Alarcón, sin embargo, no manifiesta ningún matiz de ninguna filosofía en boga durante el barroco. Su mente carece sencillamente de lo que llamaríamos una base cultural e intelectual del pensamiento europeo. Es eso, en efecto, lo que hace sus comedias tan universalistas por un lado - los mensajes de La verdad sospechosa y las otras obras afines son verdaderas y practicables en todo tiempo y todo lugar-y tan frías y mecánicas por otro. Es esa ausencia de una filosofía, entonces, más que el hacer algo nuevo, lo que ha impulsado a los críticos a alegar que "con Alarcón nace en el teatro español la comedia de caracteres" (Escarpanter 20 ), en que un vicio tipifica a un personaje y llega a ser el punto principal del drama. 
En lugar de una filosofía cómoda y reconocible, uno encuentra lo que se llamará una filosofia arbitraria, de pleno arbitrio sin ser basada necesariamente en una moral, o una relación de causa y efecto, o una determinación de justicia poética, o una idea previa de medios y fines sacada de una filosofía o ética anterior. Considerar, por ejemplo, la evidencia de unos de los dramas de Ruiz de Alarcón. En las "comedias de enredo amoroso," como La verdad sospechosa, Los favores del mundo, La industria y la suerte, Las paredes oyen y El semejante de si mismo, todas las cuales demuestran el motivo de "tres galanes y dos damas" (Ruiz de Alarcón 1:ix). No es absolutamente necesario, por causa y efecto o por justicia poética o por un sistema moral específico, que las dos bodas que terminan estas obras sean entre las personas designadas por Ruiz de Alarcón, el autor. La verdad sospechosa es un claro ejemplo de esta arbitrariedad, testigos de la cual son los numerosos artículos sobre el desenlace y sobre si García es castigado o rehabilitado por su matrimonio forzado con Lucrecia (véase, más recientemente, los de Madrigal y de Gaylord). Queda claro que los críticos no pueden decidir por qué Ruiz de Alarcón no da suficiente información, ni la correcta, para llegar a una decisión —el sistema filosófico coherente y cohesivo sobre el cual uno puede llegar a emitir un juicio moral falta en esta comedia y en la mayoría de las demás. Otro ejemplo es Mendo en Las paredes oyen, quien no gana la mano de nadie en castigo de sus chismes y mentiras; $y$, sin embargo, no hay ninguna razón lógica para que Juan gane a Ana y el conde a Lucrecia, como han observado varios críticos (Poesse 43). La obra es así tan arbitraria como las otras del mexicano.

Entre los dramas serios, se puede anotar el matrimonio sin lógica del rey Alfonso con Elvira en vez de la princesa asignada en Los pechos privilegiados, y el desenlace de La amistad castigada, con el nuevo rey resolviendo todas las intrigas amorosas de una manera totalmente casual sin relación alguna con los asuntos del drama, que causó a FernándezGuerra exclamar hace más de cien años que "los caracteres que presenta son defectuosos; y las soluciones o aplicaciones morales, injustas y contradictorias" (277).

En conclusión, hay varios aspectos de la obra dramática de Juan Ruiz de Alarcón que son bastante diferentes de la producción creativa de sus colegas españoles. Muchos parecen ser una forma de Manierismo tardío, que se puede justificar con la entrada tardía del mexicano al mundo literario del Madrid del siglo XVII; o sea, por ser un intruso. Otros, como su tratamiento de la mujer, se pueden acreditar a sus deformidades físicas o a su psicología individual. Pero la falta de un sistema filosófico-cultural del pensamiento, vista en la manipulación arbitraria de personajes, fuentes históricas, creencias religiosas, ideas de causa y efecto (¿qué es la magia sino la manipulación arbitraria de los procesos ordenados de la naturaleza, con o sin la ayuda del diablo?), coloca a nuestro dramaturgo americano muy, muy lejos del mundo histórico-cultural de los europeos y suficientemente lejos de Cervantes, Lope, Tirso, Góngora, Quevedo y Calderón para declarar que parece que "le fue imposible ser español". Esta ausencia de un sistema, o más bien esta presencia de una filosofia arbitraria, sí que se le puede atribuir a su crianza y educación en México, y a nada más. 


\section{BIBLIOGRAFIA}

Abreu Gómez, Ermilo (editor). Juan Ruiz de Alarcón: Teatro completo. México: Compañía General de Ediciones, 1951.

Alatorre, Antonio. "La mexicanidad de Ruiz de Alarcón". Anuario de Letras 4 (1964): 161-202.

Concha, Jaime. "Introducción al teatro de Ruiz de Alarcón". Ideologies and Literature 9 (1879): $34-64$.

Darst, David H. "El matrimonio y la muerte en el teatro de Tirso de Molina". Immagine riflesse: Segundo coloquio en torno a Tirso de Molina: Atti. Laura Dolfi, editora. Napoli: ESI, 1990. 221-33.

"Mannerism in Sixteenth-Century Spanish Literature". Renaissance Papers: 1981. The Southeastern Renaissance Conference, 1982. 87-95.

Delgado Morales, Manuel. "Significado político de la moral y de la justicia en El dueño de las estrellas". Josep María Solá-Solé: Homage, homenaje, homenatge. 2 volúmenes. Victorio Aguera y Nathaniel B. Smith, editores. Barcelona: Puvill, 1984. 2: 109-17.

Ebersole, Alva V., Jr. El ambiente español visto por Juan Ruiz de Alarcón. Madrid: Castalia, 1959.

Escarpanter, José A. (editor). Juan Ruiz de Alarcón: 'La verdad sospechosa'. Madrid: Playor, 1980.

Fernández-Guerra y Orbe, Luís. Don Juan Ruiz de Alarcón y Mendoza. Madrid: Rivadeneyra, 1871.

Foley, Augusta Espantoso. Occult Arts and Doctrine in the Theater of Juan Ruiz de Alarcón. Geneve: Droz, 1972.

"The Structure of Ruiz de Alarcón's La prueba de las promesas". Hispanic Review 51 (1983): 29-41.

Gaylord, Mary Malcolm. "The Telling Lies in La verdad sospechosa". MLN 103 (1988): 223-38.

Hegyl, O. 'Literary Motifs and Historical Reality in Ruiz de Alarcón's Quien mal anda en mal acaba". Renaissance and Reformation 6 (1982): 249-63.

Jiménez Rueda, Julio. Juan Ruiz de Alarcón y su tiempo. México: Porrúa, 1939.

Madrigal, José A. "La verdad sospechosa y su falsa soteriología". Círculo: Revista de Cultura 17 (1988): 129-32.

Partida, Armando. "El sincretismo indígena-hispánico de las manifestaciones parateatrales en el territorio mexicano". Cuadernos Americanos 11 (1988): 27-38.

Pasto, David J. "The Independent Heroines in Ruiz de Alarcón's Major Comedias". Bulletin of the Comediantes 40 (1988): 227-35.

Poesse, Walter. Juan Ruiz de Alarcón. New York: Twayne, 1972.

Rodríguez Cepeda, Enrique. "En torno al sentido y forma de No hay mal que por bien no venga". Renaissance and Golden Age Essays in Honor of D. W. McPheeters. Bruno Damiani, editor. Potomac: Scripta Humanistica, 1986. 205-21.

Ruiz de Alarcón y Mendoza, Juan. Obras completas. 2 volúmenes. A. V. Ebersole, editor. Valencia: Castalia, 1966. 
Severin, Dorothy Sherman. "Ruiz de Alarcón's Romantic Heroines". Golden Age Spanish Literature: Studies in Honour of John Varey by His Colleagues and Pupils. Charles Davis y Alan Deyermond, editores. London: Westfield College, 1991. 20714.

Wardropper, B. W. "La comedia española del Siglo de Oro". Con Elder Olson. Teoría de la comedia. Barcelona: Ariel, 1978. 181-242.

Weber, Alison. "La excentricidad y la norma en dos comedias de Ruiz de Alarcón". Actas del Sexto Congreso Internacional de Hispanistas. Alan M. Gordon y Evelyn Rugg, editores. Toronto: University of Toronto, 1980. 783-85. 
